\title{
Fuzzy Logic Control Design on Buck Converter for Thermo Electric Air Cooler Power Supply
}

\author{
Muhammad Wildan Alim \\ Department Electrical Engineering \\ Electronics Engineering Polytechnic \\ Institute of Surabaya \\ Surabaya, Indonesia \\ muhammadwildanalim@yahoo.co.id
}

\author{
Novie Ayub Windarko \\ Department Electrical Engineering \\ Electronics Engineering Polytechnic \\ Institute of Surabaya \\ Surabaya, Indonesia \\ ayub@pens.ac.id
}

\author{
Renny Rakhmawati \\ Department Electrical Engineering \\ Electronics Engineering Polytechnic \\ Institute of Surabaya \\ Surabaya, Indonesia \\ renny@pens.ac.id
}

\begin{abstract}
The air conditioning system that is commonly used today is an Air Conditioner (AC). however, this system is a major contributor to global warming. Often, we find that air conditioners are only used to cool only a small part of the room for individual comfort. Therefore, we need a new breakthrough from a cooling system that does not use chemicals that are environmentally friendly, namely using the Thermo Electric Cooler (TEC) cooling module by utilizing the sides. cold on the Thermo Electric Cooler (TEC). The size of the DC input voltage on the Thermo Electric Cooler (TEC) will be regulated using a buck converter with fuzzy control. When the buck converter closed loop condition with fuzzy control has a rise time value, the settling time and error percentage have a relatively better value than using the PI control. When the buck converter set point $40 \mathrm{~V}$, the minimum water temperature in the air cooler can be reached $22^{\circ} \mathrm{C}$, when the buck converter set point is $48 \mathrm{~V}$ the minimum water temperature in the water cooler can be reached $19^{\circ \mathrm{C}}$, and when the buck converter set point is $48 \mathrm{~V}$ the minimum water temperature in the air cooler can be reached $18^{\circ} \mathrm{C}$. When the water cooler uses water cooled by Peltier, the in and output air temperature decreases in temperature around $1^{\circ} \mathrm{C}$. This is due to the evaporative effect caused by water cooled by the peltier.
\end{abstract}

Keywords — thermo electric cooler, buck converter, cooler, fuzzy

\section{INTRODUCTION}

Air conditioning equipment is a necessity for humans [1]. Currently the cooling systems that are widely circulating today generally use compressor and freon systems. where the Freon gas contains chemicals that are not environmentally friendly. This should be an important concern because Freon gas can destroy the ozone layer, which endangers human life. Therefore, an alternative / new breakthrough is needed to make a cooler that is easier to make and does not use chemicals so that it is environmentally friendly, namely the use of a thermo electric module (peltier) [2].

This Peltier module requires a DC electrical energy source to get a cold and hot effect on both sides of the element, so that it can be used as needed. This Peltier module is also quite easy to use as a cooler, because basically you only need to add a heatsink and fan to reduce the hot side of the peltier [3]. However, in many previous studies, DC electrical energy sources are not equipped with a control system. This causes the Peltier module's response to be less than optimal.

This research proposes a buck converter topology that uses fuzzy control to adjust the performance of the peltier module. The peltier module will later be combined with an air cooler where the peltier module will be used to cool water in the air cooler. So it is hoped that the peltier can adjust the water temperature in the air cooler and the water cooler users do not have to bother filling the ice to maintain the cold temperature produced by the air cooler. The temperature drop in the air cooler is caused by the cooling process of the air through evaporation or so-called evaporative cooling [4].

\section{RESEARCH METODOLOGY}

\section{A. Buck Converter}

The buck converter is used to reduce the voltage to a voltage that matches the needs of the peltier module. as in figure 1 this buck converter circuit consists of several components, namely inductors, capacitors, diodes, resistors and MOSFETs as switches. When designing a buck converter, parameters are needed to obtain the correct component values in order to produce a good output. The use of incorrect component values can result in poor output, such as the appearance of too large or too small a voltage and current ripple [5]. Therefore, the following parameters in equation $(1,2,3)$.

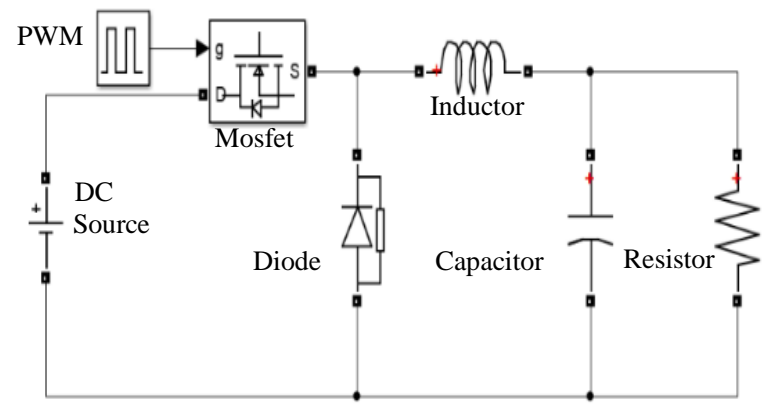

Fig. 1. Buck converter circuit

$$
\begin{gathered}
V o=V S \times D \\
L=\frac{(1-D) V o}{\Delta I L \times f} \\
C=\frac{(1-D)}{8 L\left(\Delta V_{o} / V_{o}\right) f^{2}}
\end{gathered}
$$

The meaning of the symbol above is as follows:
Vo: output voltage
Vs : input voltage
$\mathrm{D}:$ duty cycle
$\mathrm{L}$ : inductor
$\mathrm{C}$ : capacitor

TABLE I. DATA SPECIFICATION OF BUCK CONVERTER

\begin{tabular}{|l|l|}
\hline \multicolumn{1}{|c|}{ Parameter } & \multicolumn{1}{c|}{ Value } \\
\hline Switching Frequency (f) & $40 \mathrm{kHZ}$ \\
\hline Input Voltage (Vs) & $60 \mathrm{~V}$ \\
\hline Output Voltage (Vo) & $48 \mathrm{~V}$ \\
\hline Inductor (L) & $230,77 \mu \mathrm{H}$ \\
\hline Capacitor (C) & $13,5 \mu \mathrm{F}$ \\
\hline
\end{tabular}




\section{B. Control Fuzzy}

This fuzzy controller is shown so that the buck converter output voltage can be controlled according to the specified set point. Fuzzy logic control will regulate the duty cycle output of the buck converter to release the output voltage that is used in the Peltier load module. Fuzzy logic control will compare the detected output voltage value with the specified set point. So that the "error" and "delta error" values are obtained. The fuzzy output value is called the duty cycle. This value will be used to adjust the duty cycle of the buck converter [6].

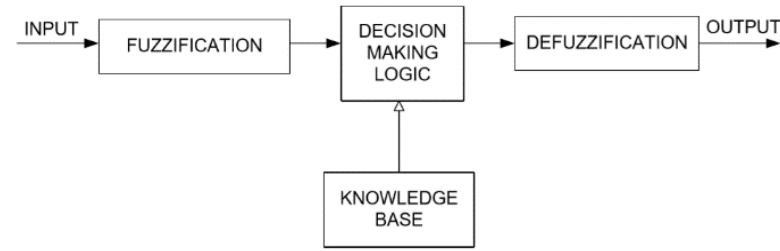

Fig. 2. Fuzzy logic controller structure

In Figure 2, the fuzzy control design which consists of a fuzzy interface system design process that includes:

a) Design input membership function.

b) Design output membership function.

c) Design rule base.

Fuzzy logic control containing domain transformation is called fuzzification. crisp input is transformed into fuzzy input. To convert crisp input into fuzzy input, the membership function must first be determined, fuzzification takes the real time value input, and compares it with the stored membership information to produce a fuzzy input value. In Figure 3 and Figure 4 the fuzzy control uses two inputs, namely error (set point-present value) and delta error (current error - previous error).

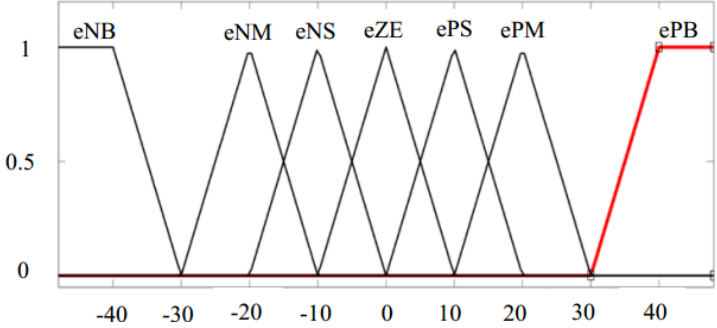

Fig. 3. Design membership function input (error)

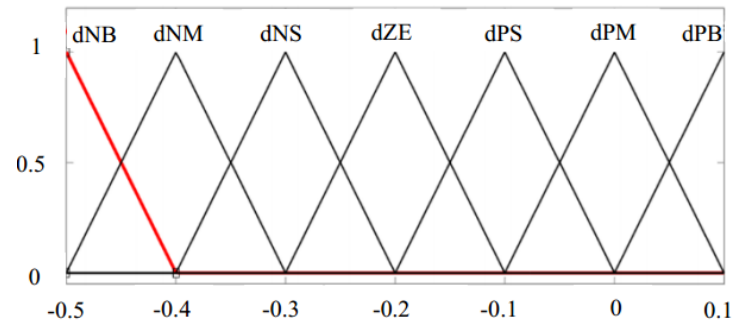

Fig. 4. Design membership function input (delta error)

In Figure 5, the membership function output duty cycle has 7 types of single tones which represent Negative Big (NB) values of -1 , Negative Medium (NM) which are valued at 0.7367, Negative Small (NS) which are worth -0.1, Zero (Z) with a value of 0 , Positive Small (PS) with a value of 0.1 , Positive Medium (PM) with a value of 0.7367. Positive Big (PB) which has a value of 1 .

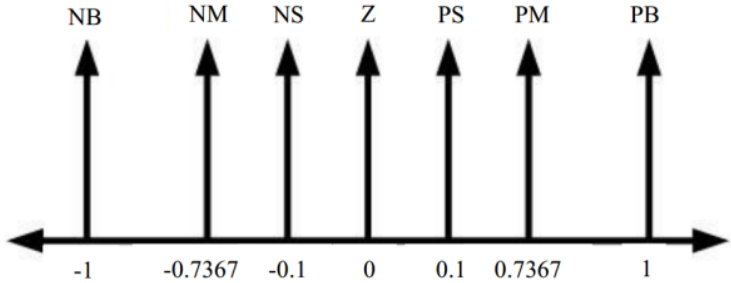

Fig. 5. Design membership function output

The use of singleton in fuzzy output is because it is easy to apply in a microcontroller and has a simple defuzzification algorithm. In defuzzification, all significant fuzzy outputs will be combined into specific output variables and comprehensive results. One of the defuzzification techniques used in this final project is the Centre of Gravity (COG). In this method, each output membership function above the value indicated by each fuzzy output is truncated. Using the COG defuzzification method, the output singleton values are combined using average weights. The COG formula for calculating the singleton reduction in equation (4).

Output $=\frac{\Sigma_{i}(\text { Output fuzzy } i) \times\left(\text { Single tone } X_{i}\right)}{\Sigma_{i}(\text { Output fuzzy } i)}$

Fuzzy rules (rule base) usually use if then statements which describe the actions taken in response to various fuzzy input. The rules follow the general behavior of the system and are written in the linguistic table pattern of membership functions. For two inputs, namely error and delta error and output duty cycle. These rules can be written in matrix form as shown in the Table II. From 7 membership functions input error and delta error, 49 rules can be generated that can determine the output value of the single tone value response to be taken [7].

TABLE II. RULE BASE

\begin{tabular}{|c|c|c|c|c|c|c|c|}
\hline $\mathbf{E} / \Delta \mathbf{E}$ & $\mathbf{N B}$ & $\mathbf{N M}$ & $\mathbf{N S}$ & $\mathbf{Z}$ & $\mathbf{P S}$ & $\mathbf{P M}$ & $\mathbf{P B}$ \\
\hline $\mathbf{P B}$ & ZE & PS & PM & PB & PB & PB & PB \\
\hline PM & NS & ZE & PS & PM & PB & PB & PB \\
\hline PS & NM & NS & ZE & PM & PM & PB & PB \\
\hline $\mathbf{Z}$ & NB & NM & NS & PS & PS & PM & PB \\
\hline NS & NB & NB & NM & NS & ZE & PS & PM \\
\hline NM & NB & NB & NB & NM & NS & ZE & PS \\
\hline NB & NB & NB & NB & NB & NM & NS & ZE \\
\hline
\end{tabular}

\section{Thermo Electric Cooler (Peltier)}

In Figure 6 shows the thermoelectric coolant component (TEC) consists of a type semi-conductors. The thermoelectric cooling component (TEC) consists of semiconductors of types $\mathrm{P}$ and $\mathrm{N}$, each of which is electrically connected, but connected $\mathrm{P}$ and $\mathrm{N}$, each of which is electrically connected, but connected thermally parallel. The working principle of the thermoelectric cooler is based on the Peltier effect, namely when DC current is flowed to the Peltier element, then one side of the Peltier, namely when the DC current is flowed to the Peltier element, then one side of the Peltier element cools (heat is absorbed) and the other side becomes the element heat. Peltier becomes cold (heat is absorbed) and the other side becomes hot (heat is released) [8].

What causes the cold side of the Peltier element to cool is the presence of electrons flowing from a lower energy level in P-type semiconductors to a higher energy level, namely $\mathrm{N}$ type semiconductors. In order for P-type electrons which have 
a lower energy level to flow, they absorb energy causing the side to cool down. [9].

In contrast to the hot side junction, electrons flow from the level higher energy levels (N-type semiconductors) to lower energy levels (P-type semiconductors). In order for electrons to flow into the P-type semiconductor, the excess energy in the $\mathrm{N}$-type is discharged into the environment, so that the side becomes hot.

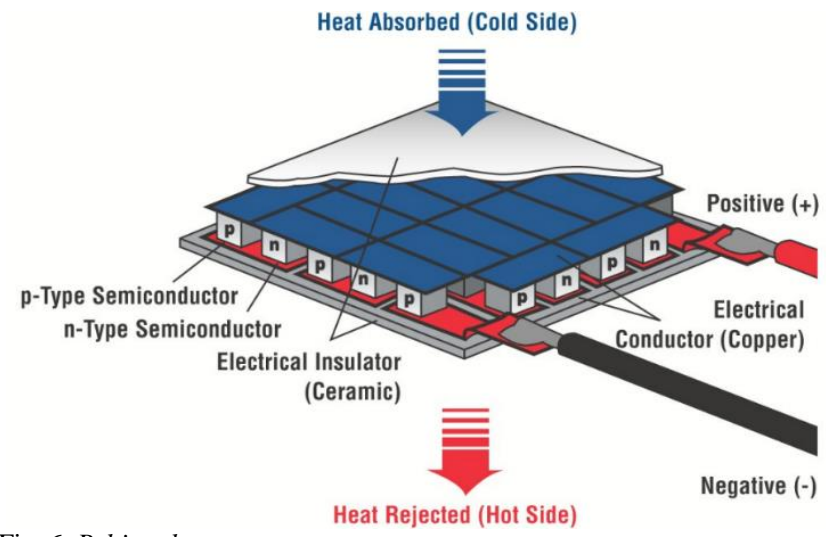

Fig. 6. Peltier element arrangement

\section{Air Cooler}

The air cooler is an electronic device that functions as an air conditioner. The air cooler can lower the air temperature. This tool can be called a cooler replacement than a fan. On the other hand, an air cooler can be an alternative to AC (air conditioner).

In Figure 7, hot air is sucked in through the back of the air cooler using a fan. Then this hot air is in direct contact with the water that has been cooled by the Peltier module which is in the cooling medium of the water cooler. Thus, hot air absorbs water particles. The amount of water absorbed depends on the humidity level of the air or the content of water particles in the air. This is where the process of cooling the air through evaporation or so-called evaporative cooling occurs. Where water molecules change form into gas molecules, and energy exchange occurs. So that the hot air temperature decreases, and the air temperature produced by the air cooler becomes cooler [10] [11].
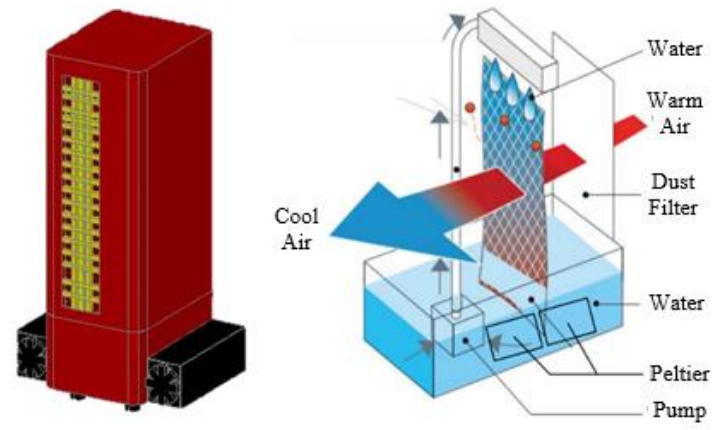

Fig. 7. Design air cooler

\section{IMPLEMENTATION RESULT}

\section{A. System Description}

Figure 8 explains that the AC voltage from PLN is converted into DC voltage using an uncontrolled FWR rectifier and is used for a buck converter voltage source. The buck converter will be controlled using 2 fuzzy controls. The fuzzy-1 control has a function to classify the water temperature in the air cooler, which later the fuzzy-1 control output will be used as the voltage set-point on the buck converter. Fuzzy-1 control uses 1 piece of feedback obtained from the temperature of the water in the air cooler. While the fuzzy-2 control has a function to improve the output characteristics of the voltage response issued by the buck converter. Fuzzy-2 control uses 1 feedback obtained from the buck converter output voltage. The buck converter output will later be used to provide supply to the peltier. The peltier will connect the 4 series units and be integrated into the water cooler system to cool the water in the air cooler.

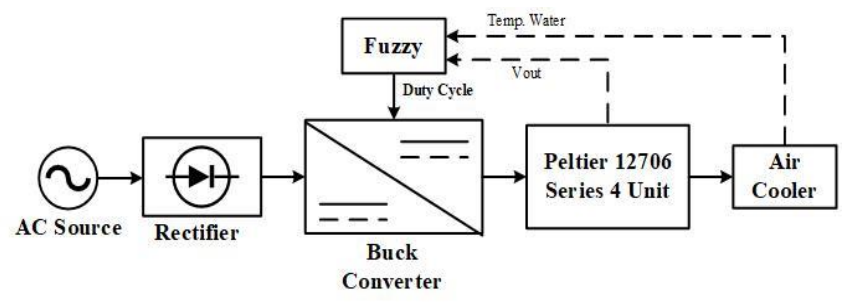

Fig. 8. Blog diagram system

\section{B. Implementation}

The hardware implementation for the buck converter for electric cooler power supply can be seen in Figure 9 which consists of several main parts, namely the buck converter, microcontroller, peltier, and air cooler. The entire hardware design refers to the system requirements.
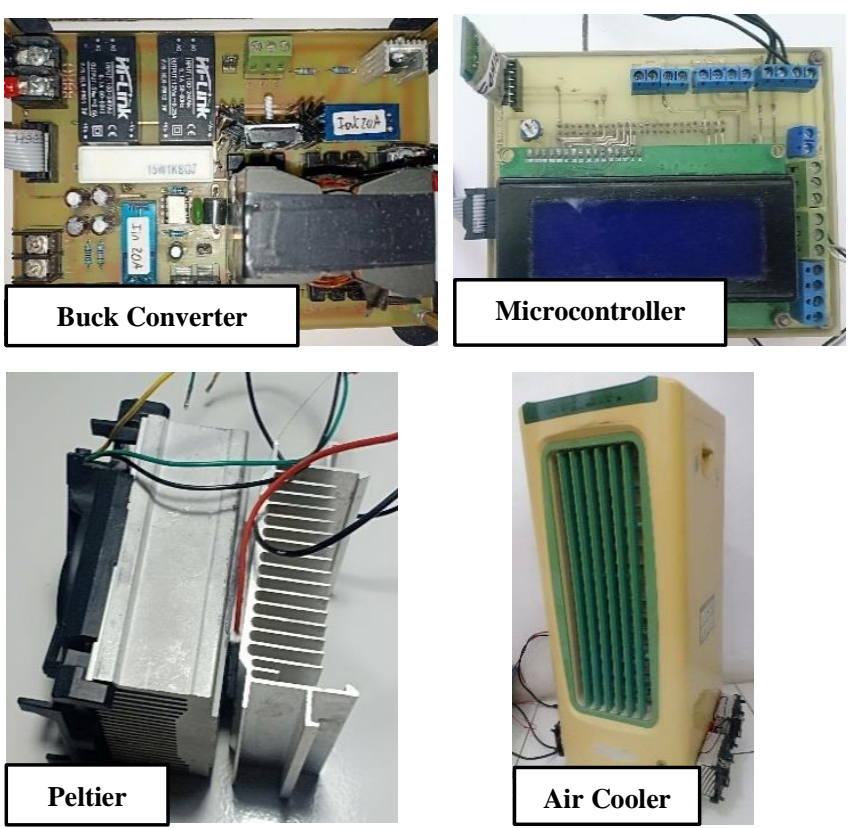

Fig. 9. Implementation of buck converter for electric cooler power supply

TABLE III. COMPONENT OF BUCK CONVERTER FOR ELECTRIC COOLER POWER SUPPLY

\begin{tabular}{|l|l|}
\hline \multicolumn{1}{|c|}{ Buck Converter } & \multicolumn{1}{c|}{ Specification } \\
\hline Switching Frequency & $40 \mathrm{kHZ}$ \\
\hline Input Voltage & $60 \mathrm{~V}$ \\
\hline Output Voltage & $48 \mathrm{~V}$ \\
\hline Inductor & $230,77 \mu \mathrm{H}$ \\
\hline Capacitor & $13,5 \mu \mathrm{F}$ \\
\hline Power & $250 \mathrm{~W}$ \\
\hline \multicolumn{1}{|c|}{ Controller } & Specification \\
\hline Microcontroller & ARM STM32F4VGTX \\
\hline Display & LCD 4x20 \\
\hline Communication & Bluetooth HC-05 \\
\hline
\end{tabular}




\begin{tabular}{|c|c|}
\hline Load & Specification \\
\hline Peltier & TEC 12706 Series 4 Unit \\
\hline
\end{tabular}

From the output of the buck converter voltage response in Figure 10 and Figure 11, it can be analyzed that the simulation of the fuzzy control system works well. This can be seen from when the room temperature feedback value is $25-28.6^{\circ} \mathrm{C}$ the converter output is worth $40 \mathrm{~V}$, when the room temperature is $28.6-31.4{ }^{\circ} \mathrm{C}$ the converter output is $48 \mathrm{~V}$, and when the room temperature is $31.4-35^{\circ} \mathrm{C}$ the converter output is $56 \mathrm{~V}$. The higher the room temperature, the greater the voltage that supplies the peltier. This is needed because when the peltier voltage is greater, the decrease in peltier temperature will be maximized so that the cooling of the water in the water cooler is maximized.

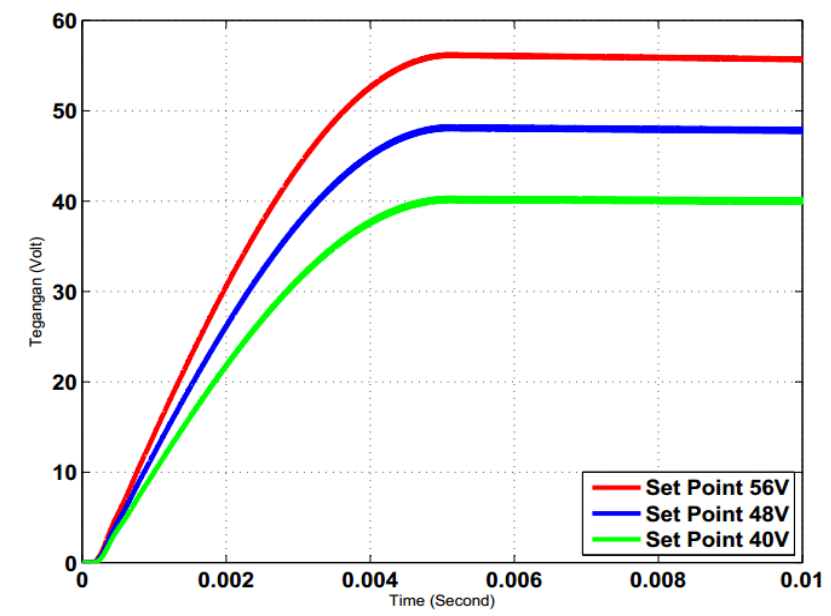

Fig. 10. The Output characteristics of buck converter voltage response close loop fuzzy logic control with different setpoints

TABLE IV. Buck CONVERTER OUtPut VOLTAGE CHARACTERISTICS Close LOOP CONTROL FUZZY

\begin{tabular}{|c|c|c|c|}
\hline \multirow{2}{*}{ Set-Point } & \multicolumn{3}{|c|}{ Parameter Output Response } \\
\cline { 2 - 4 } & $\begin{array}{c}\text { Rise Time } \\
\text { (Second) }\end{array}$ & $\begin{array}{c}\text { Settling } \\
\text { Time } \\
\text { (Second) }\end{array}$ & $\begin{array}{c}\text { Steady } \\
\text { State } \\
\text { Error (\%) }\end{array}$ \\
\hline 56 & 0,00256 & 0,0047 & $0 \%$ \\
\hline 48 & 0,00256 & 0,0046 & $0 \%$ \\
\hline 40 & 0,00258 & 0,0045 & $0 \%$ \\
\hline
\end{tabular}

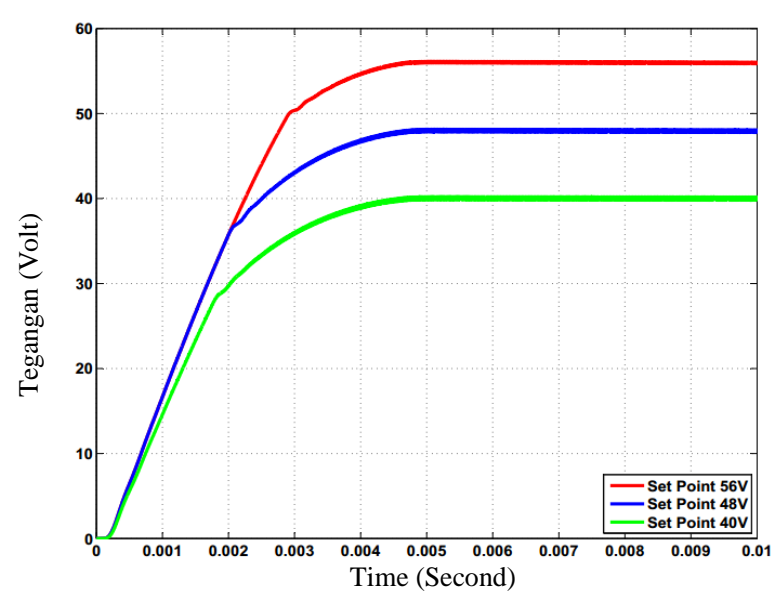

Fig. 11. The Output characteristics of buck converter voltage response close PID control with different setpoints
TABLE V. Buck CONVERTER OUtPut Voltage CHARACTERISTICS CLOSE LOOP PID

\begin{tabular}{|c|c|c|c|}
\hline \multirow{2}{*}{ Set-Point } & \multicolumn{3}{|c|}{ Parameter Output Response } \\
\cline { 2 - 4 } & $\begin{array}{c}\text { Rise Time } \\
\text { (Second) }\end{array}$ & $\begin{array}{c}\text { Settling } \\
\text { Time } \\
\text { (Second) }\end{array}$ & $\begin{array}{c}\text { Steady } \\
\text { State } \\
\text { Error (\%) }\end{array}$ \\
\hline 56 & 0,0029 & 0,0053 & $0,05 \%$ \\
\hline 48 & 0,0029 & 0,0051 & $0,083 \%$ \\
\hline 40 & 0,0029 & 0,0049 & $0,05 \%$ \\
\hline
\end{tabular}

The graph in Figure 10 and the graph in Figure 11 are the comparison of the output voltage response during the close loop fuzzy control condition with the PI control close loop condition. The test results shown in Table 3 and Table 4 show the characteristic response of the buck converter output response when the fuzzy control is compared with the PI control. When the conditions with fuzzy control have a rise time value and settling time is faster than during the PI control conditions. In addition, the steady state error value when fuzzy control has an error of $0 \%$, while when the open loop has an average steady state error value of $0.06 \%$.

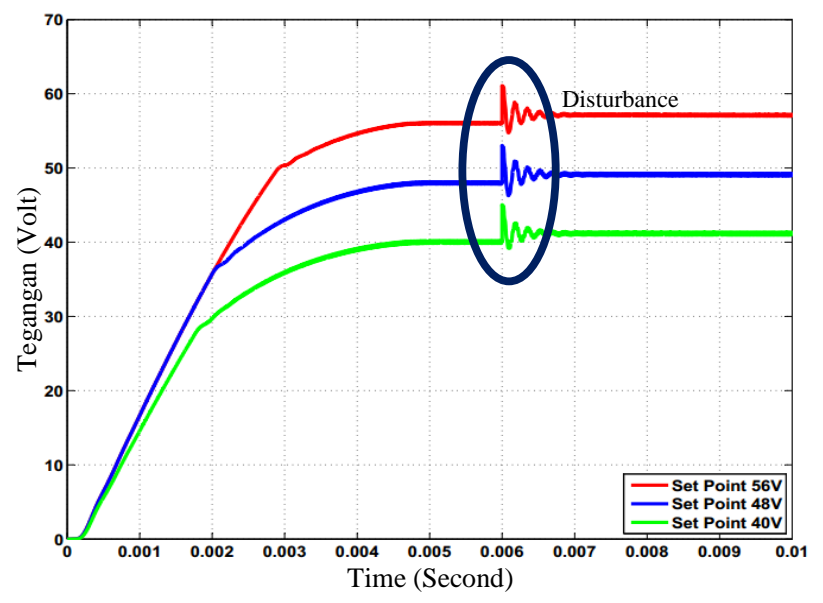

Fig. 12. The output characteristics of the buck converter voltage response close loop fuzzy logic control when given a disturbance

In Figure 12 the output buck converter voltage response with fuzzy control when given a disturbance. It can be seen that when the output voltage response is given a disturbance, the fuzzy control system can return the buck converter output response to close to the voltage set point required by the system.

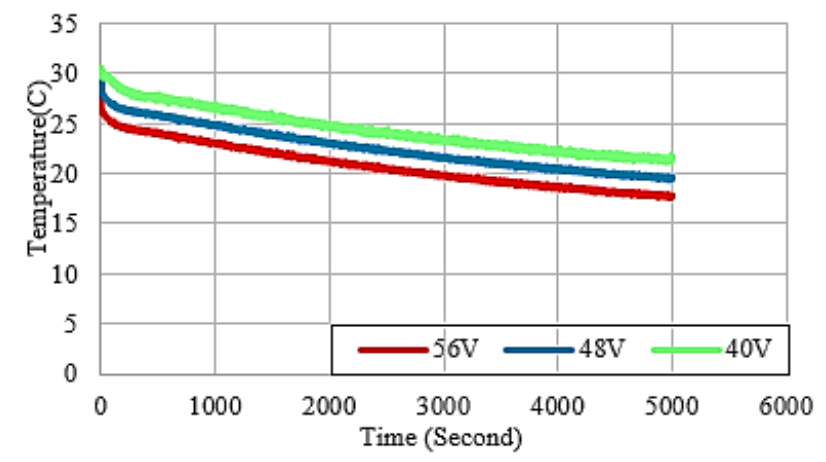

Fig. 13. The response of the water temperature in air cooler during the water cooling process with the difference in voltage at the peltier

The graph in Figure 13 is a graph of the response to the water temperature in the air cooler at 3 sets of voltage points at different peltier. From this graph, it can be seen that the 
voltage value in the peltier is inversely proportional to the water temperature in the water cooler. The greater the voltage on the Peltier, the cooler the temperature on the cool side of the Peltier, causing the cooler water in the water cooler. When the buck converter set point $40 \mathrm{~V}$, the minimum water temperature in the air cooler can be reached $22^{\circ} \mathrm{C}$, when the buck converter set point is $48 \mathrm{~V}$ the minimum water temperature in the water cooler can be reached $19^{\circ} \mathrm{C}$, and when the buck converter set point is $48 \mathrm{~V}$ the minimum water temperature in the air cooler can be reached $18^{\circ} \mathrm{C}$.

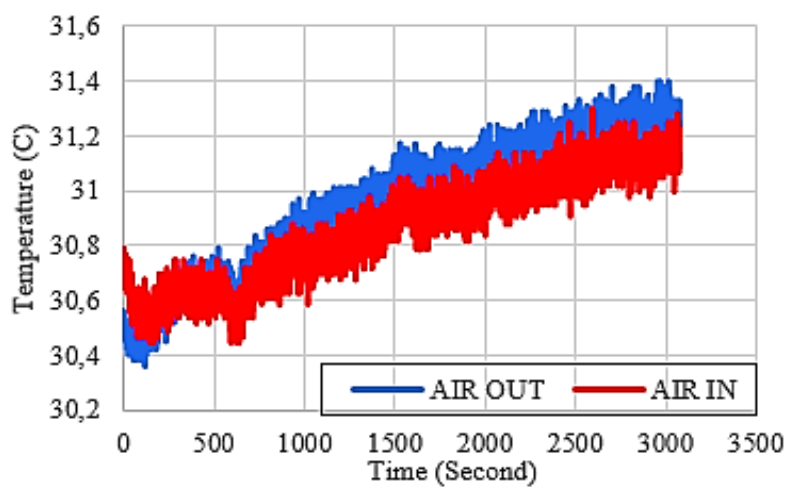

Fig. 14. The response of the output air temperature and the input air temperature in the air cooler without using water cooled by the peltier

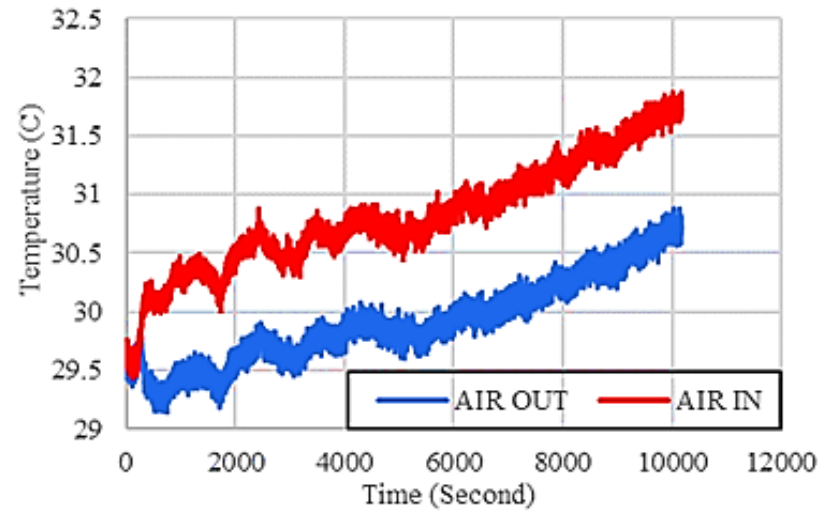

Fig. 15. The response of the output air temperature and the input air temperature in the air cooler when using water cooled by the peltier

The graph in Figure 14 and the graph in Figure 15 are graphs of the comparison of the response of air temperature in and out in the air cooler when using water cooled by Peltier and when without using water cooled with Peltier. From the two graphs above, it can be analyzed that when the water cooler uses water cooled by Peltier, the output air temperature of the air cooler is cooler than the air temperature without using water cooled by Peltier. When the water cooler uses water cooled by Peltier, the in and output air temperature decreases in temperature around $1{ }^{\circ} \mathrm{C}$. this is caused by the evaporative effect caused by water cooled by the peltier.

\section{CONCLUSION}

From the simulation results and implementation of fuzzy logic control design on buck converter for thermo electric air cooler power supply it can be concluded that:

1. When using a buck converter with fuzzy control output the voltage response has a better characteristic response than when a buck converter under the control
PI condition. At the time the steady state error value when the fuzzy control has an error of $0 \%$, while the PI control has an average steady state error value of $0.06 \%$. In addition, when using fuzzy control, the response output has a faster rise and settling time than PI control.

2. The fuzzy control on the buck converter can return the output voltage value to the set point when there is a disturbance in the system.

3. The value voltage on the Peltier module will affect the water temperature desired by the Peltier. When the buck converter set point $40 \mathrm{~V}$, the minimum water temperature in the air cooler can be reached $22^{\circ} \mathrm{C}$, when the buck converter set point is $48 \mathrm{~V}$ the minimum water temperature in the water cooler can be reached $19^{\circ} \mathrm{C}$, and when the buck converter set point is $48 \mathrm{~V}$ the minimum water temperature in the air cooler can be reached $18^{\circ} \mathrm{C}$.

4. When the water cooler uses water cooled by Peltier, the input air temperature and output air temperature of the air cooler experiences a decrease in temperature of around $1^{\circ} \mathrm{C}$. This is due to the evaporative effect caused by water cooled by the peltier.

5. Further research requires a more effective temperature cooling method system on the hot side of the peltier so that the resulting temperature on the cold side of the peltier can be maximized.

\section{REFERENCES}

[1] Melek Ozdamar, and Filiz Umarogullari, "Thermal Comfort and Indoor Air Quality," International Journal of Scientific Research and Innovative Technology, vol. 5 No. 3, March 2018.

[2] Renny Rakhmawati, Suhariningsih, Janitra Hilmyvarafi Farrasbyan, and Farid Dwi Murdianto, "Performance Robustness of PID Controller in Buck Converter For Cooling System," International Seminar on Application for Technology of Information and Communication (iSemantic), 2018

[3] Kashif Irshad, and Salem Algarni, "Study of Thermoelectric Air Duct Cooling/Heating System for Building Energy Efficient," International Conference on Energy Research and Development, November 2019.

[4] Aklilu Tesfamichael Baheta, Kar Kin Looi, Ahmed Nurye Oume, and Khairul Habib, "Thermoelectric Air-Conditioning System: Building Applications and Enhancement Techniques," International Journal of Air-Conditioning and Refrigeration, vol.27 no.2, April 2019.

[5] Ms. K Swathy, Ms. Shrutika Jantre, Ms. Yogita Jadhav, Mr. Sushil M. Labde, and Mr. Pratik Kadam, "Design and Hardware Implementation of Closed Loop Buck Converter Using Fuzzy Logic Controller," International conference on Electronics, Communication and Aerospace Technology, ICECA 2018.

[6] Zeynep Bala Duranay, and Hanifi Guldemir, "Study of Fuzzy Logic Control of Dc-Dc Buck Converter," Turkish Journal of Science \& Technology, vol. 12(2), May 2017.

[7] Saon Maity, Soham Ghosh, Rounak Pal, Sanjana Saha, Saikat Samanta, Sayan Guha, Riya Mondal, Ranjan Sau, Sadhitra Pan, Ankit Das, and Jayabrata Maity, "Performance Analysis of Fuzzy Logic Controlled DC-DC Converters," International Conference on Communication and Signal Processing, April 2019

[8] Shiv Lal, and Emarti Kumari, "Performance Analysis of a Low Price Thermoelectric Cooler: An Experimental Approach," Advances in Power Generation from Renewable Energy Sources (APGRES 2017), December 2017.

[9] Prof.Rajendra. P.Patil, Pradhyumna Suryawanshi, Akshay Pawar, and Avdhoot Pawar, "THERMOELECTRIC REFRIGERATION USING PELTIER EFFECT," International Journal of Engineering Sciences \& Research Technology, May 2017. 
[10] Bhupendra Sahare, and Chhavikant Sahu, "Design and Development of a Cooler used for Air Cooling and Refrigeration," International Journal of Recent Technology and Engineering, vol.8, January 2020.

[11] Mr. Parag Singhal, Tarun Chaudhary, Shardul Kumar Vijay, Tauheed Akhtar, Vaibhav, and Ravin Singh."Thermoelectric Air Conditioning," International Journal of Trend in Scientific Research and Development, vol. 3, April 2019. 